Puede citar este artículo como:

Narbona Vizcaíno, Rafael. «La justicia municipal en el reino de Valencia (ss. XIII-XV)». Anales de la Universidad de Alicante. Historia Medieval, N. 18 (2012-2014): 347-357, DOI:10.14198/medieval. 2012-2015.18.12

\title{
LA JUSTICIA MUNICIPAL EN EL REINO DE VALENCIA (SS. XIII-XV)
}

\author{
Rafael Narbona Vizcaíno \\ (Universitat de València)
}

\section{RESUMEN}

Las pautas marcadas por el procedimiento judicial de época foral, vigente desde el siglo XIII, caracterizan las actuaciones del Justicia o de los Justicias valencianos, como jueces locales, unas magistraturas desempeñadas por vecinos elegidos para el desempeño de tal función durante un año consecutivo. Se indican los principales hitos en la formación y transformación del oficio, así como las características legales de sus actuaciones.

Palabras clave: Justicia medieval, gobierno ciudadano, jueces locales y forales, procedimiento de la justicia medieval, magistraturas judiciales.

\section{ABSTRACT}

The guidelines marked by the judicial procedure of time foral, existing since the 13th century, characterize the actions of the Justice or of the Valencian justices, as local judges, a few courts carried out by neighbors elected for the performance of such a function for a consecutive year. Outlined the main milestones in the formation and transformation of the Office, as well as the legal characteristics of their performances.

Keywords: Medieval justice, Government citizen, local and foral judges, procedure of medieval justice, courts judicial.

Las particulares condiciones de la colonización, creadas por la monarquía tras la conquista, permitieron dotar de un marco institucional singular a la 
red urbana valenciana. Siguiendo el ejemplo pautado por la ciudad de Valencia un nuevo modelo basado en la conjunción de un gobierno colegial de magistrados (Jurats-Consell-Justícia), distribuyó las competencias necesarias para ordenar la implantación de la vida civil en el reino mediante el ejercicio de una autonomía jurisdiccional, delegada a las comunidades vecinales por Jaime I tras la conquista de las tierras islámicas, un proyecto conservado y ampliado por sus sucesores en el trono. A lo largo del siglo XIII las villas del reino de Valencia fueron imitando, y a la vez experimentando, la organización político-administrativa ensayada por la capital, de modo que fueron extendiendo un modelo particular de gestión ciudadana conforme se difundía en el territorio el fuero de Valencia, diferencial y vanguardista respecto a los demás estados de la Corona de Aragón, pues en el nuevo reino de Valencia la delegación de las competencias locales de justicia fue general para todas la villas de realengo.

Precisamente la cesión real de las competencias soberanas en materia judicial sobre la ciudad de Valencia y su término municipal supuso la creación de la justicia municipal, según una pauta cronológica detallada. Primero, con la creación del El Curia o Cort, precedente del Justicia, un oficial regio destacado para impartir justicia, ya en 1237, momento inmediatamente anterior a la toma de la capital, el cual constituyó la primera expresión organizativa de la ocupación cristiana. En un segundo momento, ese magistrado regio fue designado entre los miembros del vecindario, los cuales desde 1266 propondrían una terna de candidatos idóneos, entre los que el mismo rey o el Baile General designarían al titular para ejercer la magistratura durante un año. Y tercero, el Curia o Cort, convertido en Justicia de Valencia en torno a 1251, iría desdoblándose en otras magistraturas a lo largo del siglo XIV: el Justicia Criminal, el Justicia Civil y el Justicia de Trescientos sueldos, que distribuirían funcionalmente sus originales competencias en materias distintas.

\section{DEL PRIMITIVO CURIA O CORT A LOS JUSTICIAS VALENCIANOS}

La primera magistratura urbana de la Valencia conquistada por Jaime I fue el Curia o Cort, precedente del Justicia, anterior incluso a la toma de la ciudad, cuya función sería dirimir los conflictos de carácter civil y criminal entre los habitantes. Este Curia nacía como una magistratura de la jurisdicción real inferior, propia del área de influencia catalana, sobre todo de la Cataluña nueva, donde había ejercido un poder jurisdiccional delegado por el propio rey. De Lérida y Tortosa pasó a Mallorca y a Valencia, ciudades conquistadas que contaron desde el principio con estos jueces Curia. 
Ese oficial fue caracterizado por el profesor Jesús Lalinde como no letrado, inalienable, no delegable, irrecusable y responsable. Bien diferenciado de los oficiales territoriales como el veguer catalán o el merino aragonés, y equiparable al zalmedina, porque gozaba de una posición intermedia entre el rey que lo nombraba y la propia comunidad donde ejercía como juez urbano. Su concesión constituyó un privilegio, otorgado a localidades con importancia singular, porque este juez real, designado entre los prohombres del vecindario, adquiría así un perfil característico que beneficiaba a la colectividad, pues la libraba de agentes extranjeros o forasteros, desconocedores de las costumbres y prácticas locales.

Además de Valencia tuvieron Curia las villas de Sagunto, Burriana, Cullera y Dénia si bien, más tarde, una vez definido el modelo de gestión política e institucional de las villas reales con la actividad colegiada de Jurados-Consell-Justicia -y antes de finalizar el siglo XIII- se territorializaron los fueros propios de la ciudad a todo el reino y, con ello, se multiplicaron los justicias, implantados en todas las localidades de relevancia. Hablamos por tanto del Curia y después del Justicia como magistratura característica de las villas y ciudades de reino de Valencia.

El Curia se manifestó como cabeza organizativa y regia de la comunidad colonizadora, al menos hasta 1245 , cuando fue creado propiamente el municipio autónomo con la magistratura colegial de los Jurados. Fue entonces cuando el consilium probi hominum se transformaba en Consell, en el órgano de gobierno local presidido por los Jurados cuya primera función, la asesora en materia judicial, sería conservada por los prohombres del consistorio aun cuando el Curia terminara transformándose en Justicia, y después diera lugar a difererentes justiciazgos. Si el Curia era indefectiblemente nombrado por el rey entre los prohombres de la ciudad, desde 1266, el Justicia sería nombrado del mismo modo a partir de una terna de candidatos vecinales, presentados éstos por los Jurados de Valencia. Un privilegio de 1283 obligaba a que esa terna se obtuviera de un sorteo de candidaturas parroquiales, y así se conservaría durante todo el período foral.

La primera magistratura judicial sufriría una progresiva segregación de competencias y daría lugar a otras magistraturas: el Justicia del Grao, en 1283, elegido por los prohombres y el Justicia entre los vecinos del barrio marítimo de Valencia; el Subjusticia de Valencia, en 1307, un notario dedicado a las causas menores de treinta sueldos, que en 1321 alcanzaba hasta las valoradas hasta cincueneta y en 1363 hasta las de trescientos; finalmente, en 1321, se produjo la diferenciación de la primitiva magistratura entre el Justicia Criminal y el Justicia Civil, más el Subjusticia, cada uno de ellos con 
su asesor. Si el Subjusticia habría de ser notario, tanto el Justicia Civil como el Criminal seguirían siendo cargos no letrados.

Además del proceso de densificación y desarrollo de esas magistraturas conviene destacar la transformación del primer oficial regio o Curia en Justicia municipal, que en uno u otro caso, desde el primer momento, contaron con el consejo de los prohombres o notables locales para desarrollar su función jurisdiccional. Los privilegios reales, concedidos a los prohòms y a la universitat de Valencia confirieron rango de oficial municipal (Justicia) al primitivo oficial real (Curia). De hecho, la magistratura siempre constituyó un cargo desempeñado por un vecino elegido en el seno de la comunidad, aunque designado por el rey o su Baile.

Respecto a las funciones del Justicia cabe señalar que durante los siglos medievales, y aún todo el periodo foral que se alarga hasta 1707, el Justicia de Valencia, y después el Justicia Criminal, hacía las veces de presidente honorífico del gobierno ciudadano; mandaba pregonar y aplicar las ordenanzas municipales; era el jefe natural de la milicia urbana; ejercía de protocolario protagonista de las ceremonias urbanas; enarbolaba honoríficamente el estandarte de la ciudad; y mantenía el orden público; pero en materia judicial tan sólo ejercía como gestor de los procedimientos. El Justicia sólo actuaba a instancia de una parte perjudicada que reclamaba justicia y que, excepcionalmente, en su caso, aplicaba en la persecución de la criminalidad las leyes del rey ex oficio. Su capacidad decisoria era escasa, siempre coartada por el imprescindible asesor legal y la misma asamblea de gobierno de la ciudad o Consell, que en última instancia suscribía la inocencia o la culpabilidad en los procesos incoados mediante sentencias colegiadas, si bien el Justicia ejercía de portavoz de la misma.

El Justicia era un cargo desempeñado por un miembro de la oligarquía, caballero o ciudadano a años alternos desde 1329, elegido en la víspera de la fiesta de Navidad para ejercer de magistrado durante un año. Durante el tiempo de ejercicio de su magistratura el Justicia contaba, además de un asesor, con un lugarteniente para acompañarlo en el desempeño de sus atribuciones o sustituirlo durante su ausencia (aprobado en las Cortes de 1389); de un escribano que registraba las actuaciones en libros más o menos protocolizados según el cariz de aquéllas; de una decena de saigs, sayones o agentes, que transmitían las notificaciones judiciales o ejecutaban las detenciones, aunque carentes de cualquier iniciativa propia de un alguacil; de varios capdeguaytes o caporales que dirigían la ronda vecinal de vigilancia nocturna; y además de una red de justicias locales, elegidos entre los miembros destacados de la comunidad en cada villa o lugar del término municipal 
de Valencia, que en realidad hacían de delegados de aquél. El Justicia de Valencia los seleccionaba entre la terna vecinal propuesta y ante él tomaban posesión y juraban ejercer el cargo rectamente.

\section{LA ELABORACIÓN DEL FALLO JUDICIAL}

A este juez denominado Curia o Cort hasta 1251 y desde entonces Justicia de Valencia, competía el conocimiento de todas las causas iniciadas por los vecinos de la ciudad, ya que por su cargo y jurisdicción estaba obligado a amparar a todos los que se sintieran lesionados en sus derechos, bienes o personas. Es decir, este juez admitía todas las quejas o clams vecinales que se le presentaran para iniciar un procedimiento de solución basado en los fueros valencianos, según los cuales, nadie podía obligar a una persona a iniciar un pleito, ni siquiera el propio Justicia. La justicia valenciana se activaba exclusivamente a instancia de una parte lesionada que reclamaba la restitución de su estado y el castigo del perpetrador.

Todos los clams y todas las acciones judiciales eran registradas por el escribano del Justícia en el Libre de cort, conservados desde finales del siglo XIII para Alcoy o Concentaina, y que para la misma época en la ciudad de Valencia comenzaron a diversificarse según los distintos tipos de actos, dada la multitud de actuaciones y causas (lletres, testimonis, cèdules, penyores, demandes, requisicions, etc.). Esos clams o quejas podían haber sido presentados de viva voz o redactados por un notario o un savi en dret, pero todos quedaban registrados en los libros del Justicia, así como las diligencias o actuaciones que de él se derivaran. Inmediatamente la parte demandada era instada por el Justicia para responder verbalmente o por escrito a las acusaciones. Desde ese momento comenzaba a contar un plazo de diez días para que el clam inicial se transformara en una demanda o en una denuncia, que podría eludirse mediante la composición privada de las partes, o bien con la renuncia expresa al procedimiento ante el Justicia, circunstancias que provocaban el sobreseimiento de la causa.

Si el pleito seguía adelante, el Justicia exigía a las partes la ferma o fermança de dret con la que ambas quedaban obligadas bajo caución de bienes y personas, aportando necesariamente fiadores de ambos lados para responsabilizarse de aquéllas. De este modo la presunta parte agraviada no iniciaba demanda sin pretexto real y, de la misma manera, el presunto delincuente podría librarse de la cárcel hasta el pronunciamiento de la sentencia. Es en ese momento, en el de la ferma de dret cuando realmente se iniciaba el pleito ante el Justicia, pues desde entonces la denominada pena del quart, una cuarta parte de la cuantía en litigio, o de la pena, calonía o multa, garantizaba la 
financiación de los gastos judiciales con los bienes y fiadores obligados por cada una de las partes pleiteantes.

Desde entonces demandante y demandado aportarían los testimonios necesarios para ratificar su postura ante el Justicia, el cual asistido por su asesor y con el consejo de los Jurados y prohombres (magistrados del gobierno municipal y la asamblea ciudadana) escucharían las razones y testimonios. Los testigos podrían ser recusados por la parte contraria y también descalificada la validez de sus declaraciones, si se demostraba su nula honorabilidad, y por tanto credibilidad, pues la bona fama, vida i conversació, constituían elementos reconocidos de fuerza probatoria y testifical de los individuos.

La resolución legal del pleito se producía también ante las partes y era pronunciada por el Justicia, pero era elaborada de forma colectiva. Tanto la absolución como la condena eran pronunciadas por el Justicia tras la consulta al asesor, oídos los argumentos de las partes y escuchados los testimonios, aunque siempre junto a los Jurados y prohombres del consistorio. En aplicación taxativa de los fueros la sentencia era resultado de una decisión colectiva, la adoptada por los ediles y la élite de la comunidad vecinal representada en los órganos de gobierno de la ciudad. Al menos en teoría, el tribunal no juzgaba según su conciencia ni en cuanto pudiese conocer del asunto sino tan sólo ateniéndose a lo que las partes alegaran y probaran durante el pleito, mediante las deposiciones testificales y las razones aducidas. Es decir, el Justicia carecía de competencia para la interpretación de los hechos.

La sentencia habría de ser pronunciada en el plazo de treinta días desde la ferma de dret, salvando en su caso los aplazamientos solicitados por las partes y concedidos por el Justicia. Las posibilidades de apelación habrían de contar con el visto bueno del mismo Justicia, que podría desestimarlas sino se les otorgaba fundamento, ya que él mismo -hasta el siglo XV- recibía la primera apelación, mientras que la segunda habría de plantearse ante el mismo monarca. Si diez días después de haberse pronunciado la sentencia no se había presentado recurso la causa adquiría la condición de cosa jutgada, es decir, asunto concluido.

El procedimiento penal podía desarrollarse por dos caminos distintos. Mediante la acusación, siempre de índole privada y seguida por una acción personal con la interposición de una demanda ante el Justicia, que sujetaba al demandante a la pena del talión en caso de demostrarse la inocencia del demandado; o bien, mediante la inquisición o denuncia, desarrollada por el Justicia a instancia de una parte agraviada para averiguar o dilucidar un delito. Casi siempre se utilizaba esta vía para evitarle al demandante la pena de talión, en caso de haberse producido un delito público y notorio sin una 
evidencia clara de la identidad del criminal, pues con este procedimiento se requería al Justicia la investigación y aclaración de sospechas fundadas en casos graves definidos por los fueros (homicidio, sodomía, hurto, robo, allanamiento de morada, asalto de camino, tala de campos, incendio, lesa majestad, o falsificación de moneda). Resultó del todo extraordinaria la actuación por cuenta propia del Justicia y ésta se reservaba para casos flagrantes de crimen.

\section{LOS ASESORES DE LAS PARTES, DEL JUSTICIA Y DEL MUNICIPIO}

Primero el Curia y después el Justicia, siempre constituyeron por definición, un cargo no letrado. Según los más antiguos fueros valencianos habría de ejercer la magistratura un único vecino (un sol vehí), con cualidades sociales (probo, honrado y suficiente) y miembro de la comunidad urbana pero renovable anualmente entre la ciudadanía. El Justicia era un ciudadano en ejercicio de sus derechos civiles, electo para tal fin, y no era un juez o jurisperito profesional. Indefectiblemente el cargo fue ejercido por los líderes naturales de la sociedad urbana, es decir, por los miembros de la oligarquía, la cual hasta 1329 parece que fue exclusivamente ciudadana, pero desde ese año una decisión regia abrió el acceso a su ejercicio a los caballeros que se sometieran a los fueros valencianos, que año sí y otro no -de modo alternopodrían acceder al ejercicio de la magistratura por idéntico método.

Ese Curia o Justicia gestionó los procedimientos contando con la figura de un asesor legal, jurisperito capaz de razonar los pleitos conforme a derecho, e interpretar las leyes (los fueros aprobados en Cortes) según las competencias delegadas (los privilegios reales), de modo que el asesor constituyó un cargo anexo e imprescindible para acompañar a los justicias en el desempeño de sus funciones. Resultaba del todo inevitable que en sus quehaceres el Justicia contara con la continua colaboración de un asesor jurisperito, tal y como se ayudaban las partes que recurrían a su arbitrio judicial. Ese asesor ordinario orientó en materia de procedimientos, fueros y costumbres al Curia y después al Justicia, guiándolos en sus actuaciones por la pauta jurídica y legal, siendo nombrado directamente como cargo de confianza del magistrado cuando era elegido aquél, también para ejercer durante el periodo anual.

Inicialmente esos savis en dret, incluso notarios o entendidos en leyes, no contaron con formación universitaria. Sólo desde 1329, con la profunda reforma de las instituciones locales acometida por Jaime II, fueron imprescindibles los estudios universitarios para acceder al cargo de asesor del Justicia, desestimándose a los causidici o advocats de seca, es decir, los prácticos en el manejo de las leyes que no contaban con el grado otorgado por un examen universitario (bachiller, licenciado o doctor). No obstante, aquellos savis en 
dret sin título universitario pudieron continuar contratando sus expertos servicios con particulares, o con las mismas instituciones, siempre que hubiesen superado un examen ante un tribunal que con tal fin convocaba el municipio con regularidad.

Si el asesor del Curia o del Justicia era nombrado aleatoriamente desde 1238 por quien había sido designado como magistrado, al menos desde 1329 ese asesor habría de ser abogado, y desde 1342 el cargo sería provisto mediante un sorteo de candidatos parroquiales preseleccionados por los Jurados y los prohombres. En cualquier caso el asesor del Justicia era un cargo rotatorio y no perenne o profesionalizado, si bien la tecnificación jurídica de las magistraturas urbanas fue creciente desde principios del siglo XIV: cuatro consejeros de juristas elegidos anualmente para la asamblea ciudadana fueron creados en 1329, aunque sólo se les documenta ejerciendo desde 1344; y del mismo modo, desde 1340 se atesta la existencia de un abogado de la ciudad de Valencia, que desde mediados de la centuria ha dado paso a cuatro plazas de advocats ordinaris, como cargos de larga duración. Es decir, desde principios del siglo XIV fue consolidándose la progresiva tendencia hacia la desaparición de personas sapientes sin grado universitario en los quehaceres institucionales de los tribunales municipales.

\section{CONCLUSIÓN}

Pese a los cambios experimentados con la transformación Curia-Justicia, y la presumible reduccción de sus primitivas competencias tras la creación de los Jurados o gobierno municipal en 1245, la magistratura se convirtió en presidente de un tribunal municipal en el que ejercía de juez real. Una justicia impartida colectivamente por los prohombres de la comunidad, pues el Justicia ejercía sólo como director de los procedimientos. El consejo de los prohombres estuvo asociado a las sentencias y actuaciones del tribunal desde 1238 y de forma indefectible constituyó una dedicación característica de la asamblea ciudadana -además del gobierno político y administrativo de la ciudad- contando con el asesoramiento de sabios en derecho, abogados y después gradudados universitarios en materia legal, con el fin de aplicar los fueros valencianos.

El Justicia, prohombre elegido entre la élite de la comunidad, contaba con la colaboración en materia legal de un jurisperito, pero el fallo judicial siempre fue colectivo. El palacio de justicia era la Casa de la Ciudad, la sala de juicios era la sala de deliberaciones del Consell en el primer piso, y la cárcel, presó comuna o cadena, se encontraba en planta baja, bajo la escalera de acceso a la sala del Consell (única prisión en la que los demás oficiales 
reales, como el Baile o el Gobernador debían detener a los presos). La prisión de la torre, que estaba situada en el mismo edificio, se reservaba para casos y presos singulares o de reconocida calidad social.

El Justicia renovado anualmente mediante elecciones era uno de los miembros de la oligarquía ciudadana, pero sus sentencias pretendían ser conscientemente las de la misma comunidad, es decir, las de su gobierno ciudadano. Esta magistratura, como institución real y municipal, tenía una triple dependencia:

Económica: rendía cuentas de las multas, composiciones, redención de prendas, etc., ante el Mestre Racional, máximo oficial contable del monarca, a quien pertenecían los derechos de la justicia, excepto cuando los privilegios concedidos transferían una parte de los mismos al municipio. Hasta mediados del siglo XIV fue el Baile General quien recibía la contabilidad de la gestión.

Política: la primitiva ascencencia del Baile General sobre el municipio y sobre el Justicia se conservó incólume respecto al ejercicio de la autoridad. Los Jurados elegidos anualmente para gobernar Valencia juraban fidelidad al rey en la iglesia catedral con una solemne ceremonia, inserta en la misa mayor del día de Pentecostés, ante el máximo oficial en el reino, el Baile General. Del mismo modo el Justicia o los Justicias prestaban juramento en una ceremonia específica y similar el día de Navidad. Además los justicias civil y criminal eran seleccionados por el Baile entre la terna de nombres presentada por el vecindario.

Administrativa y judicial: el Justicia se sujetaba a las ordenanzas elaboradas por los Jurados y el Consell, garantizando su aplicación y ejecutando las sentencias colegiadas tras la deliberación de la asamblea ciudadana. El papel del Justicia o de los Justicias a lo largo del procedimiento era de guía o de gestor, y carecía de capacidad decisoria personal para iniciar procesos, salvo excepcionales actuaciones ex oficio. Además, tenía vetado aplicar tortura, absolver, condenar o liberar presos por cuenta propia. El Justicia estaba al servicio del Consell y aplicaba a través de éste por orden del Baile las órdenes del rey, siguiendo la pauta legislativa de los fueros del reino y los privilegios de la ciudad.

El Curia primero y el Justicia o Justicias después, se limitaron a recibir y presenciar las actuaciones: oía las confesiones y a los testigos junto al asesor, pero sólo junto a colectivo prohombres de la asamblea municipal de gobierno, o Consell municipal, publicaba una sentencia colegial. Su misión radicaba en oír, definir y terminar las causas junto al consejo de prohombres, es decir, la magistratura se limitaba a presentar el pleito con claridad a 
la consideración de los Jurados y consejeros, contando con la ayuda técnica del asesor, con el fin de que se dictara sentencia por parte del órgano rector de la comunidad urbana. A efectos institucionales esa sentencia resultaba de una deliberación colegial del Consell, del gobierno ciudadano. Con todo podemos concluir que los justicias valencianos se limitaban a garantizar la existencia de un foro de reclamaciones vecinales y a velar por la consecución de los procedimientos según las costumbres locales. El Justicia era un gestor, por esa razón no daba pie a la elaboración de informes jurídicos escritos, valorando las circunstancias a través de un personal técnico. De hecho, los procesos sólo recogen hitos principales de la gestión del procedimiento y no informes o valoraciones legales escritas por técnicos del derecho. En cambio los argumentos del demandante o del demandado sí estaban inspirados o presentados bajo la forma concebida por un causídico. Del mismo modo, como la sentencia resultaba de la deliberación del Consell no necesitaba de informe pericial escrito para ser incorporado al proceso, limitándose ese órgano colectivo a escuchar las indicaciones del asesor del Justicia.

\section{BIBLIOGRAFÍA}

BAÑÓ I ARMIÑANA, Ricard: Esborrany de la Cort del Justícia d'Alcoy dels anys 1263-1265. Alcoy, 1996.

BARRIO BARRIO, Juan Antonio: "Lo marginal y lo público en Orihuela a través de la acción punitiva del Justicia Criminal, 1416-1458", Anales de la Universidad de Alicante. Historia Medieval 10 (1994-1995), pp. 81-98.

DIEGUEZ SEGUí, Maria Àngels: El llibre de cort del Justícia de Valencia (1279-1321), València, 2002.

GRAULLERA SANZ, Vicente: Los primeros juristas valencianos. Valencia en la Baja Edad Media (siglos XIII y XIV), Valencia, 2000.

GREGORI, Rosa M. - GARCÍA MARSILLA, Juan V. - PUJADES, Ramon J., Llibre de la Cort del Justícia de València (1283-1287), Universitat de Valencia-Acadèmia Valenciana de la Llengua, 2008.

GUINOT RODRÍGUEZ, Enric: "Sobre la activitat del Justícia a un menut poble valencià d'inicis del segle XV: Xixona (1413)", acción punitiva del Justicia Criminal, 1416-1458", Anales de la Universidad de Alicante. Historia Medieval 10 (1994-1995), pp. 63-80.

GUINOT, Enric - DIÉGUEZ, M. Àngels - FERRAGUD, Carmel, Llibre de la Cort del Justícia de València (1280-1282), Universitat de Valencia-Acadèmia Valenciana de la Llengua, 2008.

LALINDE ABADÍA, Jesús, "El Curia o Cort. Una magistratura medieval mediterránea", Anuario de Estudios Medievales 4 (1967), pp. 169-297. 
NARBONA VIZCAÍNO, Rafael: "El Justicia Criminal. Una corte medieval valenciana, un procedimiento judicial", Estudis Castellonecs 3 (Castellón, 1986), pp. 287-310.

NARBONA VIZCAÍNO, Rafael: "Inicios de la organización político-institucional en los municipios valencianos del siglo XIII", III Congrés d'Estudis de la Marina Alta, Alicante, 1990, pp. 199-207.

PÉREZ GARCÍA, Pablo: El Justicia Criminal de Valencia (1479-1707). Una magistratura urbana ante la consolidación del absolutismo, Valencia. 1991.

PONSODA SANMARTÍN, Joan J., El català i l'aragonés en els inicis del Regne de València segons el llibre de cort del Justícia de Concentaina (1269-1295), Alcoi, 1996.

ROCA TRAVER, Francisco: El Justicia de Valencia, 1238-1321, Valencia, 1970.

ROCA TRAVER, Francisco: La jurisdicción civil del Justicia de Valencia (12381321), Valencia, 1992.

SILVESTRE ROMERO, Aureli (ed.): El Llibre de la Cort del Justícia de València (1287-1288, 1298), València, Universitat de Valencia-Acadèmia Valenciana de la Llengua, 2008. 